Published in final edited form as:

Mani, C. M., Braun, M., Molinari, V., Antonietti, M., \& Fechler, N. (2017). A High-Throughput Composite Catalyst based on Nickel Carbon Cubes for the Hydrogenation of 5-

Hydroxymethylfurfural to 2,5-Dimethylfuran. ChemCatChem, 9(17), 3388-3394.

doi:10.1002/cctc.201700506.

\title{
A High-Throughput Composite Catalyst based on Nickel Carbon Cubes for the Hydrogenation of 5- Hydroxymethylfurfural to 2,5-Dimethylfuran
}

\author{
Mani, C. M., Braun, M., Molinari, V., Antonietti, M., \& Fechler, N.
}

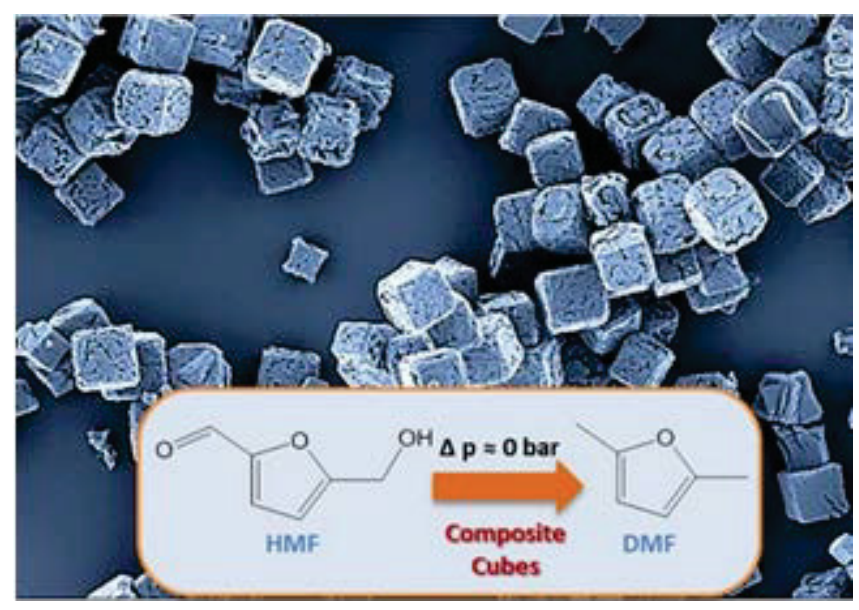

A functional nickel-carbon composite catalyst is prepared from porous carbon decorated with nickel nanoparticles. The composite catalyst possesses an unusual nanocube morphology, which allows for a good packing of a fixed-bed flow reactor. The composite cubes are tested for the hydrogenation of 5-hydroxymethylfurfural (HMF) to 2,5dimethylfuran (DMF) within a continuous-flow setup showing no significant back pressure $(\Delta p \approx 0$ bar).

This article may be used for non-commercial purposes in accordance with Wiley Terms and Conditions for Self-Archiving. 


\title{
A high-throughput composite catalyst based on Nickel carbon cubes for the hydrogenation of 5-hydroxymethylfurfural to 2,5-dimethylfuran
}

\author{
Christian Mbaya Mani, Max Braun, Valerio Molinari, Markus Antonietti, Nina Fechler* \\ Max Planck Institute of Colloids and Interfaces, Colloid Chemistry, Research Campus Golm, Am Mühlenberg 1, 14476 \\ Potsdam (Germany).
}

\begin{abstract}
A high-throughput composite catalyst is prepared from porous carbon with an unconventional nanocube morphology decorated by nickel nanoparticles. Due to the advantageous properties of the designed carbon support, the composite combines a high surface area and a hierarchical pore structure with high functionality. Furthermore, the regularly shaped nanocubes allow for a good packing of a fixed-bed flow reactor, while the internal transport pores cannot be blocked and stay open for efficient column performance. The composite is employed as catalyst in the hydrogenation of 5-hydroxymethylfurfural (HMF) to 2,5-dimethylfuran (DMF) showing good catalytic performance and overcoming the conventional problem of column blocking.
\end{abstract}

\section{Introduction}

Creative examples have revealed the powerful trick to combine different materials into a composite leading to unexpected synergistic properties of the final material.[1-3] This is especially helpful for the synthesis of catalysts such as metal species immobilized on a porous support as it allows for the unification of very different properties in one composite.[4] For example, compared to the corresponding bulk metal the composite possesses better accessible sites and increased diffusion of the reactants through the pores, hence leading to improved catalytic performance.[5-8] Furthermore, the composite synthesis enables for the homogeneous dispersion and stabilization of the supported metal compound (e.g. metal, metal carbide, metal oxide) while ensuring a large active surface area.[9-11] 
Among the various types of support materials, carbons with a hierarchical pore structure have attracted much attention in heterogeneous catalysis.[6,12-14] This is due to their widely tunable properties, structuring possibilities and availability.[5, 15-17] With regard to catalytic applications, threedimensional (3D) hierarchical pore structures with interconnected micro-, meso- and macropores are crucial to overcome transport limitations and to ensure good heat and mass transfer throughout the pore system. This impacts not only the activity but also the selectivity and stability of the composite catalyst.[18]

With regard to the catalytic setup, so-called fixed-bed reactors are very advantageous as they allow for reactions in a continuous flow which in turn is beneficial in terms of low operating costs and high conversion rates per unit mass of catalyst. Nonetheless, most of the current publications and state of the art research still involve batch mode processes and hence are not appropriate for usage in high throughput set-ups. The reason for the dominance of batch reactors is the difficulty to fill columns effectively, and especially column blocking by the debris of catalyst particles is a regular event. Good packing with high plate numbers is challenging and requires careful design of the packing material. In industry and on the larger scale, this is commonly approached by the use of catalysts pressed or extruded as pellets. Yet, these catalytic systems often exhibit low surface areas $\left(<150 \mathrm{~m}^{2} \mathrm{~g}^{-1}\right)$ which result in lower catalytic activity when compared for instance to lab scale catalysts $\left(>1000 \mathrm{~m}^{2} \mathrm{~g}^{-1}\right)$.[19-21] Moreover, pellets are often brittle and fail over time due to mechanical point stress due to packing, leading to increased pressure drop.[22] As bead packing and mechanical strength are important properties for industrial catalysts,[23-26] engineers are tackling this problem by the development of better palletization techniques, i.e. optimized size and shape, and more resistant materials.[27-30] As discussed in various reports for inorganic materials, a regularly structured catalyst allows for an improved packing in fixed-bed reactors and hence a reduced pressure drop.[31-33] For the lab scale and the involved much smaller reactive columns, a careful design of the catalyst morphology at the micrometer scale is mandatory. Thereby, the main advantage of pelletized catalyst such as negligible pressure drop can be combined with the benefits of a powder catalyst, i.e. high surface area, and low mechanical stress. However, conventional synthesis strategies for hierarchically porous carbon composite materials are laborious and involve templating, post-synthetic activation steps, and often subsequent metal loading.

Recently, we reported a synthesis strategy for the preparation of hierarchically porous carbon materials derived from the crystals of the coordination complex of zinc ( $\mathrm{Zn}$ ) ions and squaric acid (SA).[34] These primary crystals determine the structural properties of the final carbon already before the conversion to carbon providing a porous carbon material with a unique 3D-cube morphology, an inner hierarchical 
pore system and a high specific surface area. Because of these structural features, such carbon microparticles offer great potential for efficient fixed-bed reactor packing and good catalytic performance.

In this work, we extended this system towards a composite catalyst composed of a hierarchically porous carbon support and nickel nanoparticles (Ni-NPs) and show that indeed that pressure drop issues and the plate number in such a packed bed reactor are favorable for catalysis. The catalytic flow-system is then exemplified in a reaction of high importance in biorefinery, i.e. the hydrogenation of 5-hydroxymethylfurfural (HMF) to yield 2,5-dimethylfuran (DMF), which is considered as one of the most promising biofuels and platform chemical of the near future.[35-36]

\section{Results and Discussion}

Squaric acid (SA) is a strong dibasic acid and is predominantly present as a dianion in aqueous solutions. It contains four electron donating oxygen atoms which are beneficial in the design of 3D-coordination structures and exhibits non-classical aromaticity of the building block. SA tends to form stable metaloxocarbon complexes when coordinated to metal ions.[37] Inspired by this, we recently synthesized crystals with some unique 3D cube morphologies based on a squaric acid-zinc complex (SAZn).[34] Heat treatment of $\mathrm{SAZn}$ at $900{ }^{\circ} \mathrm{C}$ in a nitrogen $\left(\mathrm{N}_{2}\right)$ atmosphere and subsequent washing in an acid solution yields a porous carbon (PC) material (SAZn_PC) which possesses a hierarchical pore structure under retention of the cube morphology with inner cavities of fractal-like structure. For the composite synthesis, this carbon was impregnated with an aqueous solution of $\mathrm{Ni}\left(\mathrm{NO}_{3}\right)_{2} 6\left(\mathrm{H}_{2} \mathrm{O}\right)$ by using an incipient wetness impregnation method and subsequent reduction in $\mathrm{H}_{2} / \mathrm{Ar}$ atmosphere.

In order to prove the structural retention of the composite after the composite synthesis step, the morphology of the particles was studied by scanning electron microscopy (SEM, Figure 1). Here, it can be seen that the 3D cube morphology of the initial porous carbon SAZn_PC was maintained even throughout the Ni-impregnation process (Figure $1 \mathrm{~b}$ ). This already hints to the good stability of the carbon microparticles at elevated temperatures $\left(475^{\circ} \mathrm{C}\right)$ and throughout impregnation treatment. 

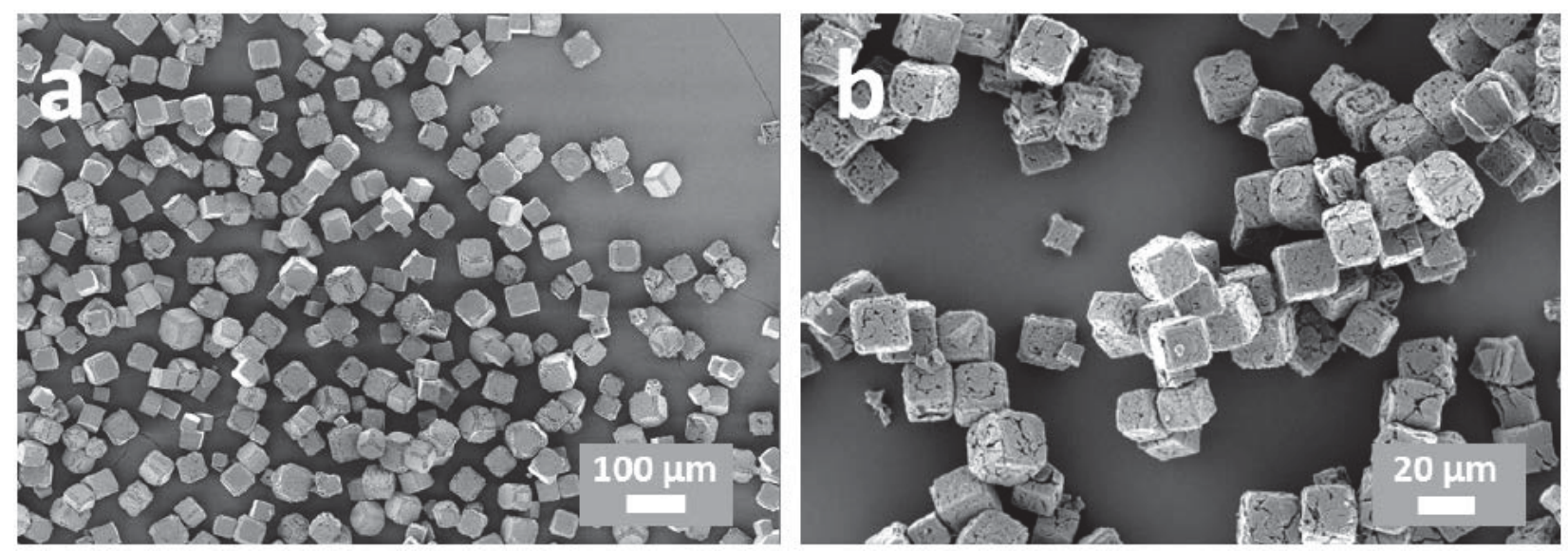

Figure 1.SEM images of (a) SAZn_PC and (b)Ni@SAZn_PC.

Insights into the formation of the 3D cubes were gained by crystallographic analysis of the SAZn complex using X-ray diffraction (XRD) (Figure 2). In accordance with crystallographic data from the International Centre for Diffraction Data (ICDD) (Figure $\mathbf{2 d}$ ), the crystalline SAZn units are composed of $\mathrm{Zn}\left(\mathrm{H}_{2} \mathrm{O}\right)_{2}\left(\mathrm{C}_{4} \mathrm{O}_{4}\right)$.[38] Here, the complex is constituted of $\mathrm{Zn}$ atoms coordinated by four squarate units and two water molecules in trans-position to each other in a slightly distorted octahedron. The squarate units are incorporated in a bridging bis- $(\mu-1,3)$ coordination motif leading to $\mathrm{Zn}$-squarate chains linked by strong intermolecular hydrogen bonds which form a 3D Zn-squarate framework. [39-40] The differences in the relative intensities of the XRD patterns of SAZn compared to the corresponding database is due to differences in the preferential growth of the crystal.

The diffractogram of SAZn_PC exhibits a weak and broad reflection at $2 \theta=25^{\circ}$ which can be attributed to the (002) plane of the carbon. This is characteristic for a locally disordered, graphitic carbon and hence confirms that the crystals were successfully converted to the corresponding carbon material. After the $\mathrm{Ni}$ decoration, XRD of the catalyst Ni@SAZn_PC reveals reflections at $2 \theta=44.5^{\circ}$ and $52^{\circ}$, which are assigned to the (111) and (200) crystalline planes of $\mathrm{Ni}^{0}$, respectively.[41] No reflection characteristic of oxides could be observed from the diffractograms, which confirms the absence of crystalline nickel oxide species and the successful reduction of $\mathrm{Ni}\left(\mathrm{NO}_{3}\right)_{2} 6\left(\mathrm{H}_{2} \mathrm{O}\right)$ to metallic $\mathrm{Ni}$. The average crystalline domain size of the Ni-NPs was calculated from the (111) reflection using the Debye-Scherrer formula whereby a crystallite size of $11.5 \mathrm{~nm}$ was determined.[42] 


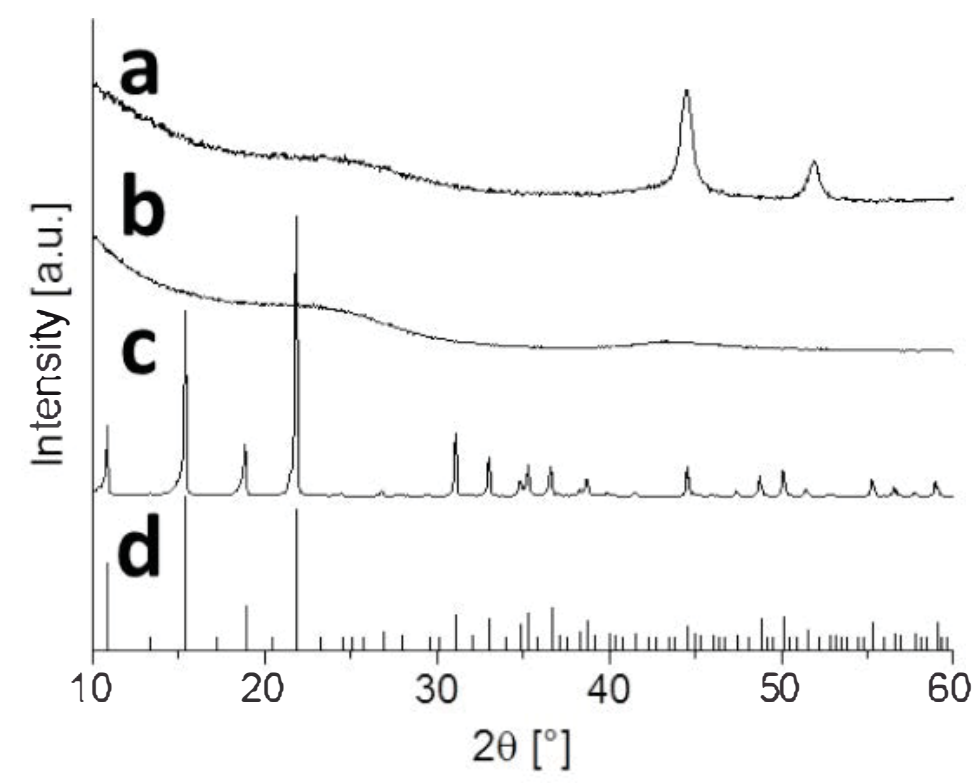

Figure 2. XRD patterns of (a) the composite catalyst Ni@SAZn_PC, (b) the carbon support SAZn_PC, (c) the complex SAZn and (d) the database pattern for SAZn (PDF 04-017-7412).

Elemental Analysis (EA) and Inductively Coupled Plasma Optical Emission Spectroscopy (ICP-OES) of the resulting composite catalyst Ni@SAZn_PC reveal a Ni-loading of 15 wt. \% (Table S1 in SI). In spite of a slight decrease of the relative carbon content, this further supports the successful composite formation. The residual zinc content in the final carbon is $0.1 \mathrm{wt} \%$ and together with the applied conditions, this is negligible with regard to potential influences on the composite catalyst.

In order to obtain more insights on the nanostructure of the composite, Transmission Electron Microscopy (TEM) images of Ni@SAZn_PC are presented in Figure 3. On the one hand, the images reveal the carbon support to be constituted of a very light carbon structure including homogeneously distributed, larger pores. This regular network is attributed to the synthesis in which the crystalline precursor induces the pre-alignment into a well-distributed pore structure. On the other hand, TEM images also show the homogeneous loading of the Ni-NPs onto the carbon support with an average size of $12 \mathrm{~nm}$. This is consistent with the determined nickel crystallite size obtained from XRD pattern and elemental mapping images revealing the cubes to be constituted by carbon and nickel nanoparticles (Figure $3 \mathrm{c}, \mathrm{d}$ ). 

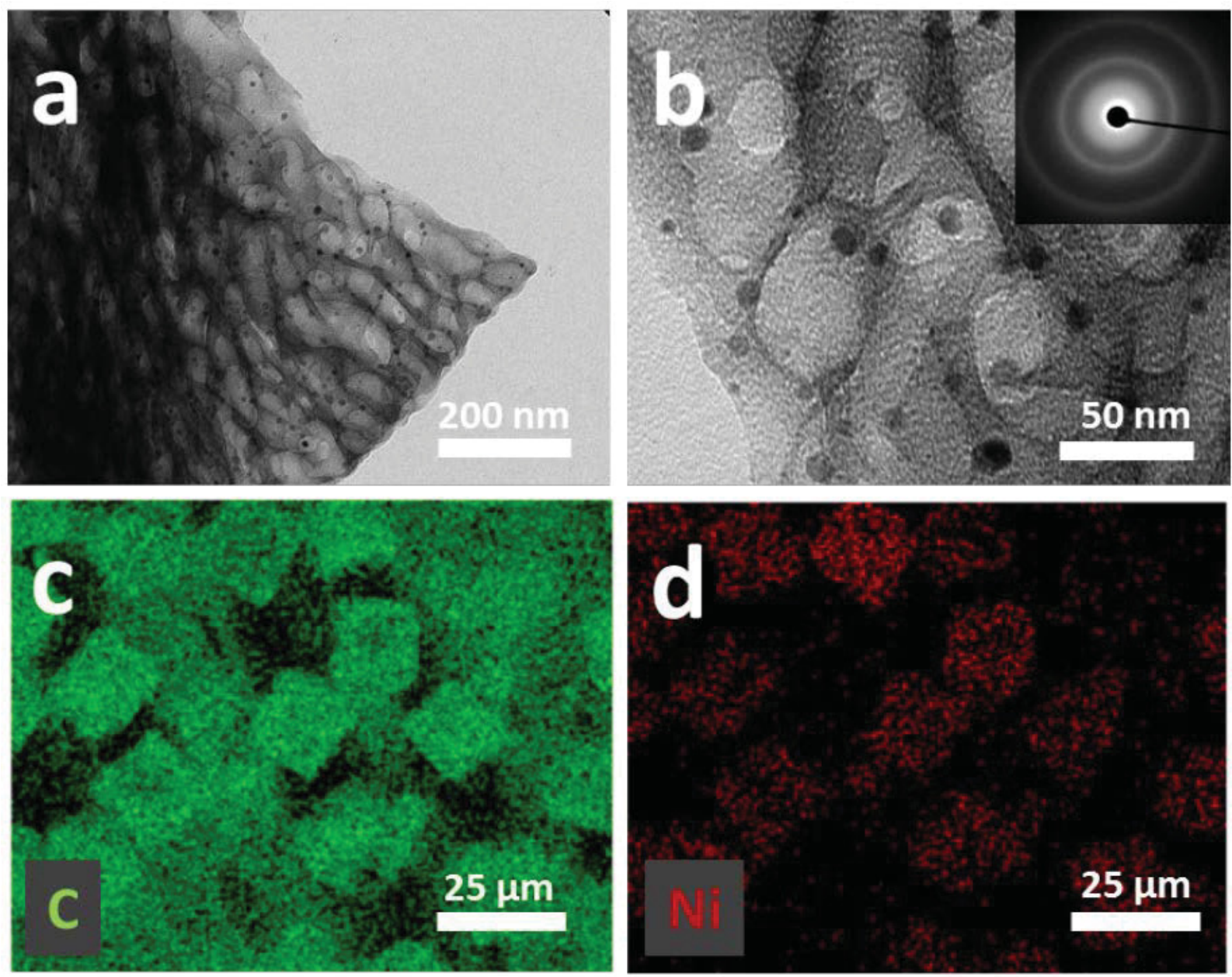

Figure 3. TEM images of $(a, b)$ the composite catalyst Ni@SAZn_PC and $(c, d)$ EDX elemental mapping of Ni@SAZn_PC with C and Ni.

Nitrogen sorption experiments were performed in order to determine the influence of nickel impregnation on the porosity of the final composite, (Figure 4, Table S2 (SI)).

Here, the final composite catalyst Ni@SAZn_PC still reveals a high surface area of $1291 \mathrm{~m}^{2} \mathrm{~g}^{-1}$ compared to the initial carbon material $\left(1423 \mathrm{~m}^{2} \mathrm{~g}^{-1}\right)$ and a total pore volume of $1.55 \mathrm{~cm}^{3} \mathrm{~g}^{-1}$. The slightly decreased apparent surface area together with the overall very similar isotherm shape show that almost all original carbon pores are still accessible. The decreased surface area is therefore attributed to the higher averaged material density upon nickel decoration. This is further supported by the comparison of the porosity parameters (Table S2 in SI) which reveal that the hierarchical pore structure of the carbon support material originally comprised of micro- and mesopores is maintained even after the Ni-loading. Eventually, the pores of the carbon support and the Ni-NP sites are still accessible for the reactants. 


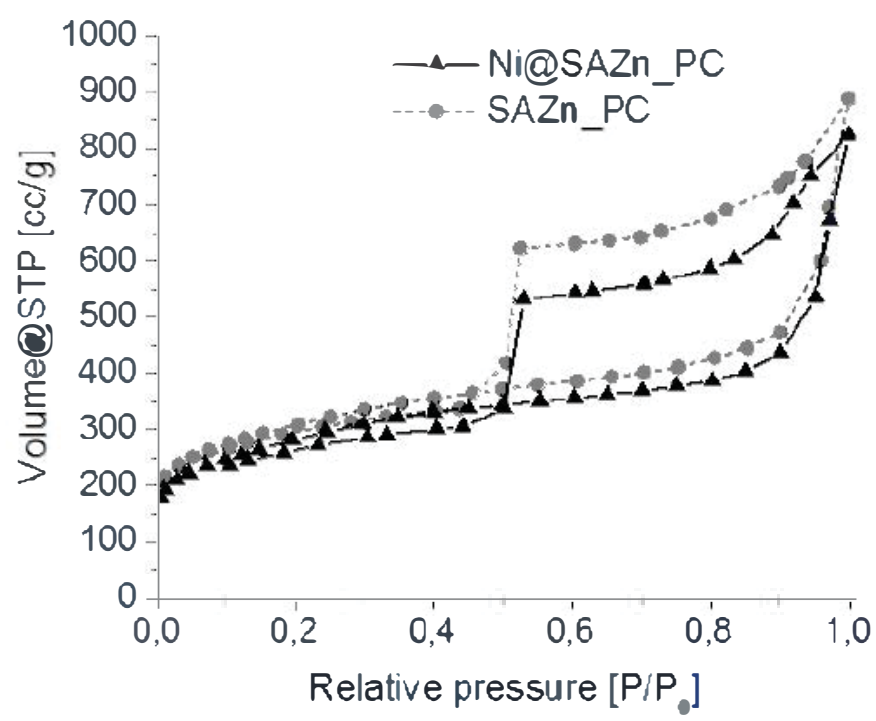

Figure 4. $\mathrm{N}_{2}$-sorption isotherms of Ni@SAZn_PC (black solid line) and SAZn_PC (grey dashed line).

As the composite is a promising candidate for catalytic applications, Ni@SAZn_PC was exemplarily applied as catalyst in the selective hydrogenation of HMF for the production of DMF. For this, the composite catalyst was loaded in a lab-scale hydrogenation flow reactor called $\mathrm{H}$-Cube Pro ${ }^{\mathrm{TM}}$ and the pressure drop of the system was investigated at various parameters (Table 1).

Table 1: Pressure studies on Ni@SAZn_PC (159 mg, 15 wt\% Ni) at different conditions in the flow system without using hydrogen; $P_{\text {inlet }}:$ pressure at the entrance of the column; $\mathbf{P}_{\text {set }}$ : pressure adjusted for the column; all measurements were performed using ethanol.

\begin{tabular}{cccc}
\hline $\mathrm{T}\left[{ }^{\circ} \mathrm{C}\right]$ & $\mathrm{P}_{\text {:et }}[\mathrm{bar}]$ & $\mathrm{F}\left[\mathrm{ml} \mathrm{min}^{-1}\right]$ & Pinlet $[\mathrm{bar}]$ \\
\hline 60 & 6 & 0.50 & $6-7$ \\
100 & 6 & 0.50 & $6-7$ \\
120 & 6 & 0.50 & 6 \\
140 & 6 & 0.50 & $6-7$ \\
150 & 6 & 0.50 & $6-7$ \\
\hline 150 & 6 & 0.50 & $6-7$ \\
150 & 10 & 0.50 & $10-11$ \\
150 & 14 & 0.50 & $14-15$ \\
150 & 18 & 0.50 & $18-19$ \\
150 & 30 & 0.50 & 30 \\
\hline 150 & 6 & 0.25 & 6 \\
150 & 6 & 0.50 & $6-7$ \\
150 & 6 & 0.75 & $6-7$ \\
150 & 6 & 1.00 & 7 \\
150 & 6 & 2.00 & $9-10$ \\
\hline
\end{tabular}


Here, the monitoring of the back pressure applying different temperatures $\left(60^{\circ} \mathrm{C}\right.$ to $\left.150{ }^{\circ} \mathrm{C}\right)$, pressures ( 6 bar to 30 bar) and flow rates $\left(0.25\right.$ to $\left.2.0 \mathrm{ml} \mathrm{min}^{-1}\right)$ revealed negligible pressure drops at all conditions ( 0 to 1 bar). Compared to pressure drops of about 100 bar which are often observed with the $\mathrm{H}$-Cube Pro $^{\mathrm{TM}}$ using fine powder catalysts in such a flow system, the highest back pressure (3-4 bar) which was measured with $2 \mathrm{~mL} \mathrm{~min}$ flow rate at $150{ }^{\circ} \mathrm{C}$ and 6 bar is negligible.[43] This promising result is attributed to the combination of a high pore volume and the presence of also larger pores of the catalyst, but also its homogeneous micrometric morphology. Besides the backpressure, the theoretical plate model gives further information on the processes in a packed column. Following the principles of column chromatography, the number of theoretical plates $\mathrm{N}$ in a column is a measure of the column efficiency which, among others, is a function of the materials properties, of the column packing, and of the column dimensions.[44-46] Here, high numbers of theoretical plates are associated with high column efficiency. Exemplarily, $\mathrm{N}$ was determined for the column packed with the Ni@SAZn_PC based on the retention time of toluene (equation 1 ), where $t_{R}$ is the retention time of toluene and $w_{H}$ is the peak width at half maximum.[46]

$$
N=5.545 \times\left(\frac{t_{R}}{w_{H}}\right)^{2}
$$

The composite material revealed a high $\mathrm{N}$ value of 751 compared to the $\mathrm{N}$ value of 9 for a commercial carbon black under the same conditions. For the composite, a narrow Gaussian peak and a retention time of approximately 2 min were observed with toluene (Figure.5). In contrast, the column packed with commercial carbon black revealed a broad and asymmetrical peak with a retention time of $36 \mathrm{sec}$ (Figure 5). 


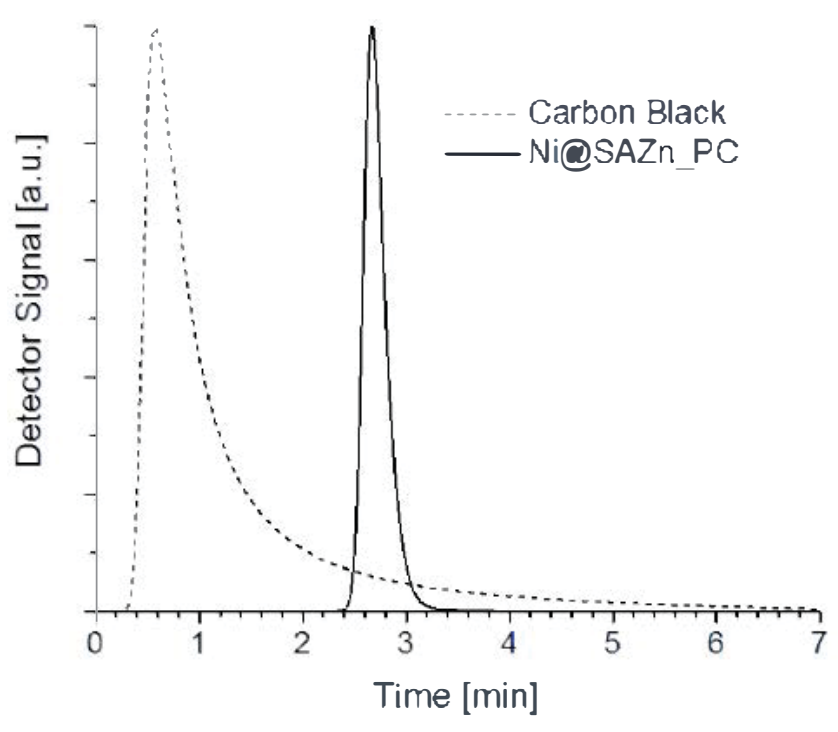

Figure 5. Chromatogram of toluene in a column packed with carbon black (dashed line) and the composite Ni@SAZn_PC (solid line).

These initial tests support the hypothesis that the herein presented composite cubes are superior to amorphous powders when used as a column material in a flow reactor.

The catalytic column was then employed for the conversion of HMF to DMF (Table 2 and Figure 6) as an example for an important reaction in biorefinery, i.e. the upgrade of carbohydrates to fuels (DMF) and platform chemicals. The deposited nickel nanoparticles are an excellent candidate for hydrogenation reactions due to its abundance and low cost when compared to noble metals such as Pt, Pd, Ru etc.

Table 2: Overview of applied parameters and results for the conversion of HMF (0.05 M in Ethanol) to DMF using Ni@SAZn_PC (159 mg, $0.4 \mathrm{mmol} \mathrm{Ni})$ as catalyst. The pressure of the system was kept at 6 bar ( $\Delta \mathrm{p}$ [bar] back pressure).

\begin{tabular}{|c|c|c|c|c|c|c|}
\hline $\begin{array}{c}\text { HMF } \\
\text { Ni-CUBES } \\
\text { Entry }\end{array}$ & $F\left[m L \min ^{-1}\right]$ & $X[\%]$ & $\mathrm{Y}_{\mathrm{DMF}}[\%]$ & $\mathrm{S}_{\mathrm{DMF}}[\%]$ & $\Delta p$ [bar] & $\begin{array}{c}\text { Productivity } \\
{\left[\mathrm{mmol}_{\mathrm{OMF}} \mathrm{h}^{-1} \mathrm{~g}_{\mathrm{cat}}{ }^{-1}\right]}\end{array}$ \\
\hline 1 & 0.25 & 100 & 41 & 41 & 0 & 1.9 \\
\hline 2 & 0.5 & 79 & 68 & 86 & $0-1$ & 6.3 \\
\hline 3 & 0.75 & 56 & 50 & 89 & $0-1$ & 7.08 \\
\hline 4 & 1.0 & 35 & 33 & 94 & 1 & 6.14 \\
\hline
\end{tabular}




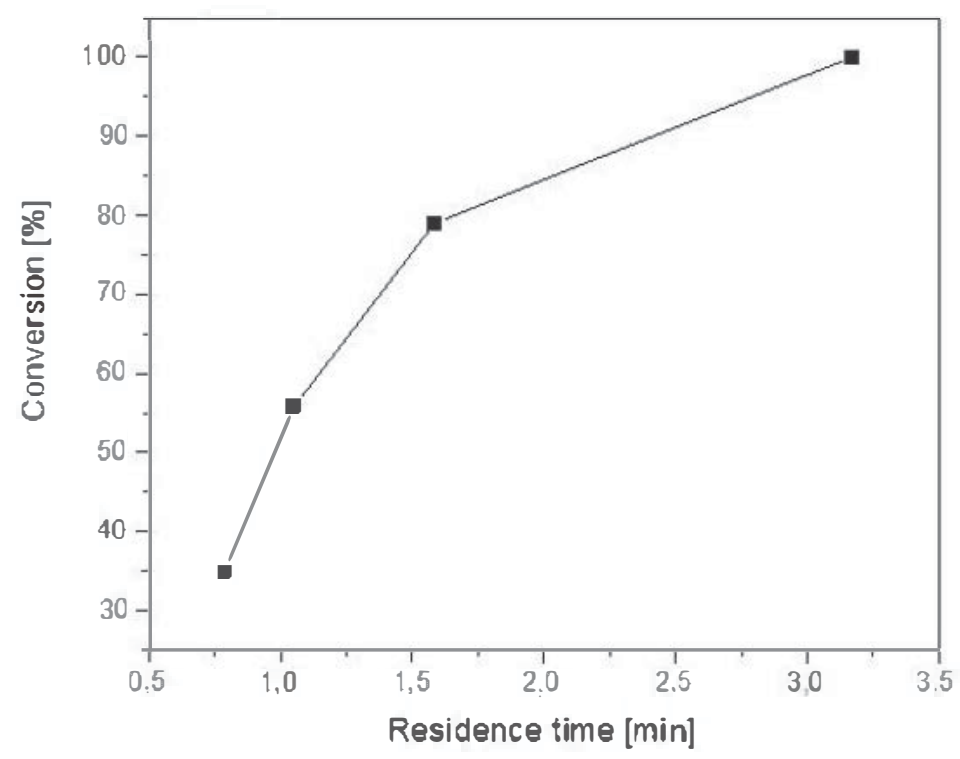

Figure 6: Dependency of conversion over residence time at $150{ }^{\circ} \mathrm{C}$ and 6 bar converting $\mathrm{HMF}$ to DMF over 159 mg Ni@SAZn_PC.

Activity and hence conversion of substrates always depend on the residence time when using a flow system. With the nickel based catalyst (Ni@SAZn_PC) this dependency is shown for $150{ }^{\circ} \mathrm{C}$ in Figure 6, where the reaction is so fast that it complies with our flow set-up (1/e conversion below 2 min). Longer residence times come with increasing conversion. Practically full conversion of HMF was measured at a flow rate of $0.25 \mathrm{~mL} \mathrm{~min}^{-1}$, corresponding to a contact time with the catalytic system of 3.2 minutes. Additionally, the yield and selectivity are given. With higher flow rates between 0.5 and $1.0 \mathrm{mLmin@1}$ the reaction reached around 90\% selectivity towards DMF. With an increased flow, the conversion dropped to $35 \%$ owing to reduced residence time in the column, whereas the selectivity stayed high and no significant back pressure was observed. The reaction looks like a typical first order kinetics, i.e. the reaction runs rather ideally. Besides the conversion, the productivity is another figure of merit and our setup showed a maximum of $7.08 \mathrm{mmol} \mathrm{gcat}^{-1} \mathrm{~h}^{-1}$ at around $0.75 \mathrm{~mL} \mathrm{~min}^{-1}$, calculated on the base of the full mass of the catalyst, i.e. the weight of the carbon as well as of the employed nickel. In order to compare the results of the presented catalyst and to classify the results in a broader context, the material was listed against different other catalysts from literature (Table 3). 
Table 3: Overview and comparison of hydrogenolysis of HMF to DMF with different catalysts.

\begin{tabular}{|c|c|c|c|c|c|c|c|c|c|}
\hline Entry & Catalyst & $\begin{array}{l}\text { Loading } \\
\text { [mg] }\end{array}$ & $\begin{array}{c}\mathrm{H}_{2} \\
{[\text { bar] }}\end{array}$ & $\begin{array}{c}\mathrm{T} \\
{\left[{ }^{\circ} \mathrm{C}\right]}\end{array}$ & $\begin{array}{c}\text { conv } \\
{[\%]}\end{array}$ & $\begin{array}{l}\text { Time } \\
\text { [min] }\end{array}$ & Mode & $\begin{array}{l}\text { Productivity } \\
{\left[\mathrm{mmol}_{\text {DMF }} h^{-1} g_{\infty 0 t}^{-1}\right]}\end{array}$ & Ref \\
\hline 1 & PtCo@HCS & 50 & 10 & 160 & 100 & 120 & batch & 19.20 & [47] \\
\hline 2 & $\mathrm{Pd} / \mathrm{C} / \mathrm{Zn}$ & 50 & 8 & 150 & $>99$ & $8 \mathrm{~h}$ & batch & 8.40 & [48] \\
\hline 3 & $\begin{array}{l}\text { Ni@SAZn_ } \\
\text { PC }\end{array}$ & 159 & 6 & 150 & 56 & $\sim 1$ & conti & 7.08 & $\begin{array}{l}\text { this } \\
\text { work }\end{array}$ \\
\hline 4 & $\mathrm{Ni}-\mathrm{W}_{2} \mathrm{C} / \mathrm{AC}$ & 120 & 40 & 180 & 100 & 180 & batch & 2.50 & [49] \\
\hline 5 & $\mathrm{Ni} / \mathrm{AC}$ & 155 & 40 & 180 & 100 & 180 & batch & 0.97 & [49] \\
\hline 6 & $\mathrm{Ru} / \mathrm{Co}_{3} \mathrm{O}_{4}$ & 100 & 10 & 150 & $>99$ & $24 \mathrm{~h}$ & batch & 0.60 & [50] \\
\hline
\end{tabular}

Most research on the production of DMF published until now presents only data of batch reactions. To make our continuous system comparable to the state of the art, the productivity was calculated referring the product to reaction time and mass of catalyst. Noble metals such as platinum-cobalt or palladium show naturally the highest productivity due to the high reactivity of these expensive noble metals. Notably, in spite of using the non-precious nickel in this work, Ni@SAZn_PC reveals a comparable performance even to $\mathrm{Pd}$-based catalysts. Furthermore, the composite catalyst exhibited the highest productivity among other nickel based catalysts (7.08 vs. maximum $2.5 \mathrm{mmol} \mathrm{h}^{-1} \mathrm{~g}_{\mathrm{cat}}{ }^{-1}$ ) even when more strict reaction conditions are used (longer reaction time, higher temperature and pressure).The comparably low costs together with the low back pressure in the flow reactor make indeed the presented nickel composite a promising candidate for continuous set-ups for biomass upgrade.

The composite Ni@SAZn_PC was used over 15 h of reaction under variable conditions without showing any significant decrease in catalytic activity, nor an increase of back pressure, which was the main focus of this work. The porous cube structure guarantees a continuous flow over all this time, which was further proved with an additional $21 \mathrm{~h}$ experiment using $150^{\circ} \mathrm{C}, 6 \mathrm{bar}$, as well as $0.25 \mathrm{mLmin} \mathrm{Lnd}^{-1}$ a hydrogen flow of $30 \mathrm{mLmin}^{-1}$. After the first long experiment, the reactor column was opened in order to recover the catalyst and investigate the influence of the reaction on the cubes. Most part of the cubes retained their initial cube morphology (Figure S4 in SI), while some "sharp fragments" were found. The latter is very unusual for fractured carbon materials as they usually possess rather random morphologies. Eventually, this hints to the partial fracture of the carbon cubes into pieces throughout column packing which, however, retain main characteristics of the cube-shaped carbons thus keeping 
the catalyst performance. Additionally, as catalysts are dynamic systems during catalysis, it is also possible that partial rearrangement of the Ni particles affected the stability of the carbon. The energy input in form of temperature, pressure or convection also leads to the growth of bigger $\mathrm{Ni}$ - particles on the expense of the smaller ones first seen at the outer surface of the cubes and ascribed to Ostwald ripening (Figure S5 in SI). The TEM image of the recovered composite catalyst shows also the inner parts of the catalyst and reveals an increased average particles size of $22 \mathrm{~nm}$ in diameter (Figure 7b). Yet, in contrast to the outer species, these nanoparticles are still homogeneously distributed and thus possess good contact to the carbon support. However, the initial metallic Ni phase was observed also after the reaction as detected by XRD (Figure 7c). A crystallite size of $25 \mathrm{~nm}$ in diameter was calculated from the (111) reflection at $2 \theta=44.5^{\circ}$ by applying the Debye-Scherrer equation which is in good agreement with the particle size determined by TEM.

Nitrogen sorption analysis of the recovered composite catalyst revealed a decreased surface area and total pore volume, accounting for $580 \mathrm{~m}^{2} \mathrm{~g}^{-1}$ and $0.92 \mathrm{~cm}^{3} \mathrm{~g}^{-1}$ compared to $1291 \mathrm{~m}^{2} \mathrm{~g}^{-1}$ and $1.55 \mathrm{~cm}^{3} \mathrm{~g}^{-1}$ of the initial composite catalyst. However, the nitrogen sorption isotherm of the used catalyst confirms the retention of meso- to macropores (Figure 7d). This speaks for partial pore blocking, most presumably due to a side reaction, i.e. HMF condensation, which forms humins in all analyzed cases. [51] 

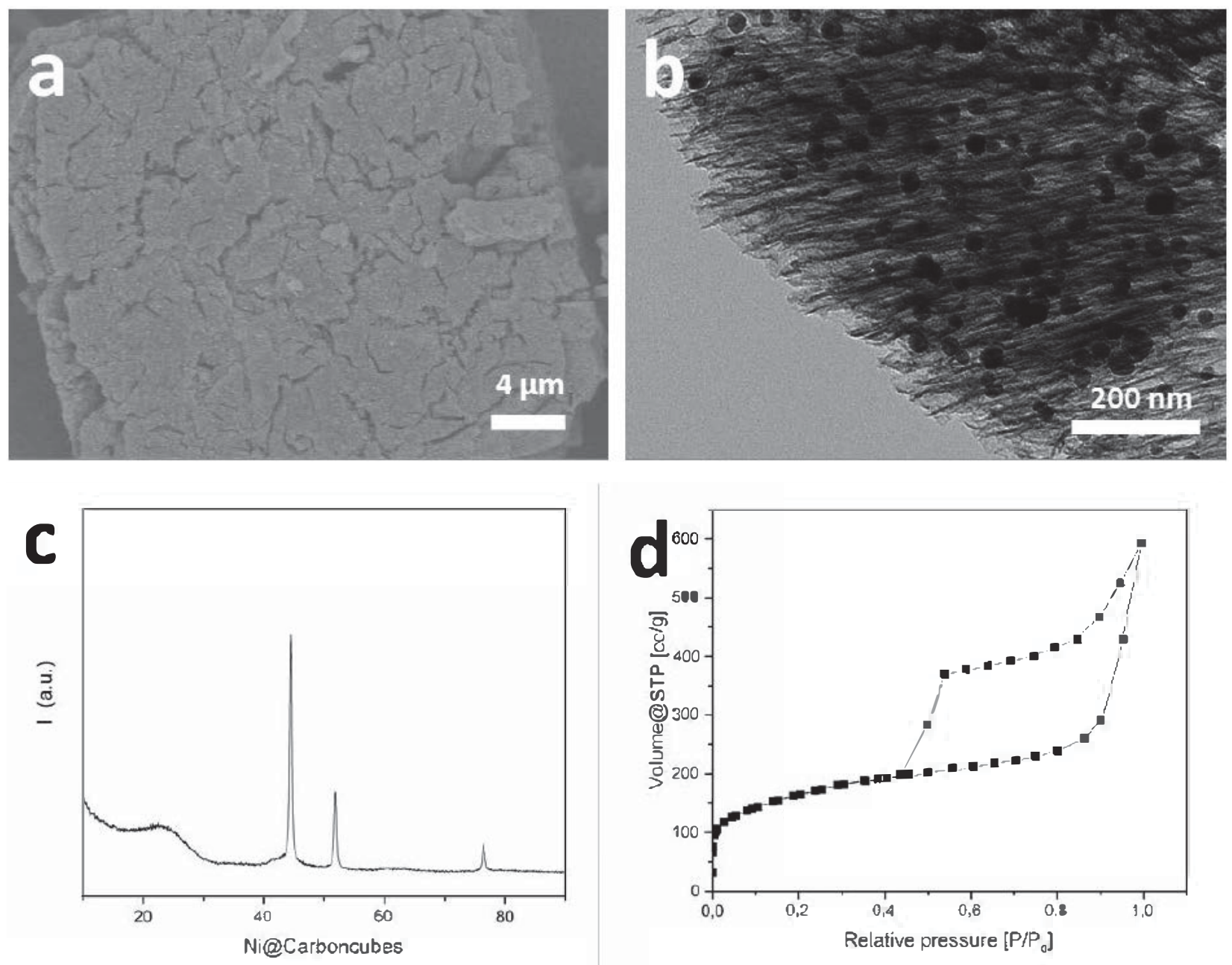

Figure 7: (a) SEM image of the composite catalyst Ni@SAZn_PC recovered after 15 hours of reaction, (b) corresponding TEM image (c) its diffractogram and (d) nitrogen sorption isotherm.

It is the micropore contribution which is blocked, presumably first by HMF adsorption, then by the byproducts of the reaction, which is common for other flow systems.[S2] This is supported by the isotherm shapes where the closure of desorption branch is shifted to lower relative pressures for the used composite compared to the initial material, as well as the reduction of the "micropore intercept" by about $50 \%$. Interestingly, this loss of micropores is usually not coupled to a significant decrease of performance of the catalyst, as fluid reactions usually do not rely on those pores (too small for fluid transport, in contrary to gases). The nickel content quantified in the recovered catalyst after 15 hours did not change significantly (14.5wt\% compared to the initial $15 w t \%)$ which further explains the constant activity of the catalyst and the weakness of nickel leaching even under the applied high temperature conditions. Thereby, the nickel carbon cubes are able to efficiently serve for the hydrogenation of HMF 
to DMF within a flow reactor setup even over extended operation times without significant pressure drop and materials failure. This is attributed to the special cube morphology including a special internal micro- as well as mesoporosity as well as a homogeneous nickel particle distribution.

\section{Summary}

A functional nickel-carbon composite with an unusual cube-shaped morphology and high porosity was synthesized from rather cheap, readily available and safe precursor squaric acid followed by nickel immobilization. These cubes possess a high specific surface area, a high total pore volume and a hierarchically porous structure consisting of interconnected micro-, meso- and macropores.

The composite cubes were then tested for the hydrogenation of HMF to DMF within a continuous flow setup. Due to the special morphology, the composite cubes revealed promising performance in terms of packing and maximal productivity, which was found to be even comparable to precious metal catalysts. Especially the negligible pressure drop and the hierarchical porosity allow for the performance of hydrogenation reactions over longer time, indicating the usability in upgrading biomass derived compounds in continuous flow reactors. Taking into account the variety of metal species that can be deposited onto the fundamental carbon cube tectons, the herein presented synthesis approach offers a promising route also for other catalytic reactions and opens the access to other flow conversion reactions.

\section{Acknowledgement}

The authors wish to thank UNICAT, the German Excellence Cluster for Catalysis, as well as the Max Planck-Fraunhofer cooperation Initiative "Dendrorefining" for financial support. 


\section{References}

[1] J. Liang, Y. Zheng, J. Chen, J. Liu, D.H. Jurcakova, M. Jaroniec, S.Z. Qiao, Angew. Chem. 2012, 124, 3958-3962.

[2] N. Fechler, T.P. Fellinger, M. Antonietti, Chem. Mater. 2012, 24 (4), 713-719.

[3] T.Y. Ma, S. Dai, M. Jaroniec, S.Z. Qiao, Angew. Chem. Int. Ed. 2014, 53, 7281-7285.

[4] J. Liu, N.P. Wickramaratne, S.Z. Qiao, M. Jaroniec, Nat. Mater., 2015, 14, 763-774.

[5] H. Yang, S.J. Bradley, A. Chan, G.I.N. Waterhouse, T. Nann, P.E.Kruder, S.G.Telfer, J. Am. Chem. Soc. 2016,138, 11872-11881.

[6] T. Umegaki, Q. Xu, Y. Kojima, Materials, 2015, 8, 4512-4534.

[7] E. Lam, J.H.T. Luong, ACS Catal. 2014, 4, 3393-3410.

[8] Y. Yuang, K. Chiang, N. Burke, Catal. Today 2011, 178, 197-205.

[9] A. Seidel, J. Loos, N. Boddenberg, J. Mater. Chem. 1999, 9, 2495-2498.

[10] N. Patel, R. Fernandes, S. Gupta, R. Edla, D.C. Kothari, A. Miotello, Appl. Catal. 8 2013, 140-141, 125-132.

[11] V. Molinari, C: Giordano, M. Antonietti, D. Esposito, J. Am. Chem. Soc. 2014 136, 1758-1761.

[12] C.M.A. Parlett, K. Wilson, A.F. Lee, Chem. Soc. Rev. 2013, 42, 3876-3893.

[13] F. R. Reinoso, Carbon 1998,36, 159-175.

[14] B. Fang, J. H. Kim, M. Kim, J.S. Yu, Chem. Mater. 2009, 21 (5), 789-796.

[15] M. Kim, S. Hwang, J.S. Yu, J. Mater. Chem. 2007, 17, 1656-1659.

[16] X. Xu, Y. Li, Y. Gong, P. Zhang, H. Li, Y. Wang, J. Am. Chem. Soc. 2012, 134 (41), 16987-16990.

[17] X.H. Li, M. Antonietti, Chem. Soc. Rev. 2013,42, 6593-6604.

[18] Y.G. Lin, Y.K. Hsu, S:Y. Chen, L.C. Chen, K.H. Chen, J. Mater. Chem. 2010, 20, 10611-10614.

[19] Y.M. Park, D.W. Lee, D.K. Kim, J.S. Lee, K.Y. Lee, Catal. Today 2008, 131, 238-243.

[20] J.T. Richardson, Y. Peng, D. Remue, Appl. Catal., A. 2000, 204, 19-32.

[21] E.H. Lee, Catalysis Reviews, 1974, 8:1, 285-305.

[22] Y. Li, D. Wu, Y.S. Lin, China Partic. 2004, 2 (2), 53-62.

[23] S.P.S. Andrew, Chem. Eng. Sci., 1981, 36 (9), 1431-1445.

[24] P.J. Denny, M.V. Twigg, Stud. Suf. Sci. Catal. 1980, 6, 577-599.

[25] S. Ergun, Chem. Eng. Prog. 1952, 48, 89-94.

[26] J.W. Fulton, Chem. Eng. 1986, 93 (19), 71-77.

[27] D. Zhang, P. Fan, D. Wu, Y. Li, China Partic. 2005, 3, 23.

[28] M.F. Mathias, G.P. Muldowney, Chem. Eng. Sci. 2000, 55 (21), 4981-4991.

[29] F. Doraia, M. Rolland, A. Wachs, M. Marcoux, E. Climent, Procedia Eng. 2012, 42, 1335-1345. 
[30] A. Burghardt, A. Kubaczka, Chem. Eng. Process 1996, 35 (1), 65-74.

[31] M. Nijemeisland, A.G. Dixon, AIChE J. 2004, 50, 906-921.

[32] G. Gaiser, V. Kottke, Chem. Ing. Tech. 1989, 61, 729-731.

[33] K.M. Brunner, H.D. Perez, R.P.S. Peguin, J.C. Duncan, L.D. Harrison, C.H. Bartholomew, W.C. Hecker, Ind. Eng. Chem. Res. 2015, 54, 2902-2909.

[34] C.M. Mani, T. Berthold, N. Fechler, Small 2016, 21, 2906-2912.

[35] Y. Román-Leshkov, J.N. Chheda, J.A. Dumesic, Science 2006, 312 (5782), 1933-1937.

[36] Y. Román-Leshkov, C.J. Barrett, Z.Y. Liu, J.A. Dumesic, Nature 2007, 447, 982-985.

[37] O. Kovalchukova, S. Strashnova, Rev. Inorg. Chem. 2014, 34(1), 1-24.

[38] S. Neeraj, M.L. Noy, C.N.R. Rao, A.K. Cheetham, Solid State Sci.2002, 4, 1231-1236.

[39] A.Weiss, E. Riegler, I. Alt, H. Böhme, C. Robl, Z. Naturforsch. 1986, 18-24.

[40] O.M. Yaghi, G. Li, T.L. Groy, J. Chem. Soc. Dalton Trans. 1995, 727-732.

[41] F. Davar, Z. Fereshteh, M. Salavati-Niasari, J. Alloys Compd. 2009, 47, 797-801.

[42] J.I. Langford, A.J.C. Wilson, J. Appl. Cryst. 1978, 11, 102-113.

[43] M. Al-Dahhan, F. Larachi, M. Dudukovic, A. Laurent, Ind. Eng. Chem. Res. 1997, 36, 3292.

[44] N. Tanaka, H. Kobayashi, N. Ishizuka, H. Minakuchi, K. Nakanishi, K. Hosoya, T. Ikegami, J. Chrom. A 2002, 965, 35-49.

[45] K.K. Unger, W. Messer, J. Chrom. 1978, 149, 1-12.

[46] H. Determann, Gel Chromatography, 2nd Ed., Springer-Verlag, New York, 1969, 71 pp.

[47] G.H. Wang, J. Hilgert, F.H. Richter, F. Wang, H-J. Bongard, B. Spliethoff, C. Weidenthaler, F.Schüth, Nat Mater 2014, 13, 293-300.

[48] B.Saha, C.M. Bohn, M.M. Abu-Omar, ChemSusChem 2014, 7, 3095-101

[49] Y.B. Huang, M.Y. Chen, L. Yan, Q.X. Guo, Y. Fu, ChemSusChem 2014, 7, 1068-72

[50] Y. Zu, P. Yang, J. Wang, X. Liu, J. Ren, G. Lu, Y. Wang, Appl. Catal., 8 2014, 146, 244-248.

[51] B. Hu, K Wang, L. Wu, S-H. Yu, M. Antonietti, M-M. Titirici, Adv. Mater. 2010, 22, 813-828.

[52] M. Braun, A. Antonietti, 2017, Continuous flow process for the production of 2,5-dimethylfuran from fructose using (non-noble metal based) heterogeneous catalysis, Manuscript submitted for publication

[53] M. Thommes, Chem. Ing. Tech. 2010, 82 (7), 1059-1073. 